\title{
THE FUTURE OF RESTAURANT REVENUE MANAGEMENT
}

\author{
Sheryl E. Kimes \\ School of Hotel Administration \\ Cornell University \\ Ithaca, NY
}

Jonathan Beard

Pricing and Revenue Management

Walt Disney Parks and Resorts

Orlando, FL

\begin{abstract}
Although hotels and restaurants have expressed strong interest in implementing restaurant revenue management (RRM), data, change management and system integration issues have often stymied their efforts. The intent of this article is to present a framework for understanding the various aspects of RRM in a full-service restaurant and to identify fertile areas for future research. We present RRM as a building consisting of five pillars. The foundation consists of the company's internal infrastructure of data, decision support tools, systems and internal culture, while the five pillars consist of the traditional four Ps of marketing (product, promotion, price and placement) along with a fifth $\mathrm{P}$, people.
\end{abstract}

KEYWORDS: restaurants, studies, customer relationship management, managerial skills, revenue management 


\section{INTRODUCTION}

Restaurant revenue management (RRM) has been discussed for the past 15 years and a number of articles on the topic have been published (Kimes et al , 1998; Bertsimas and Shioda, 2003; Kimes, 2004, 2005; Thompson, 2010). Although hotels and restaurants have expressed strong interest in implementing RRM, data issues, change management issues, lack of system integration and the lack of a specialized RRM system have often stymied their efforts. Our intent in this article is to present a framework for understanding how to implement RRM in a full-service restaurant and to identify fertile areas for future research.

A helpful way of viewing revenue management (RM) is as a building consisting of five pillars. The foundation consists of the company's internal infrastructure while the five pillars consist of the traditional 4 Ps of marketing (product, promotion, price and placement) along with a fifth $\mathrm{P}$, people.

\section{INFRASTRUCTURE}

The infrastructure has four basic components: the data, decision support tools, systems and the internal culture. Each will be discussed in more detail below.

\section{Data}

Accurate, granular and timely data is essential for RM. Key transactional data categories for RM for full service restaurants include accurate party size information, accurate check opening and closing times, accurate check amounts, accurate information on the menu items ordered and information on the method of payment. In addition, for restaurants that take reservations, information on when people booked their reservations as well as their party size is crucial for accurate forecasting and optimization. 
The transactional level data is available in the restaurant's Point of Sales System (POS) system, but is often difficult to extract. Because of this, several Business Intelligence (BI) companies (for example, Avero, Ctuit) have emerged that extract and synthesize POS data. In addition, the data is often inaccurate. Inaccurate party size information can be caused by server error or by the way in which the restaurant defines a 'cover' (many restaurants define a cover as an entrée). Meal opening and closing times might be inaccurate because of server error or the lack of availability of POS terminals.

Reservation data has become more computerized over the past 10 years. This computerization has provided restaurants with more accurate information on who has made reservations, when they made their reservation and their party size. In addition, with some of the reservation systems, restaurants have the ability to track information on customer preferences, customer contact details and no-show behavior.

Reservations data rarely connected to POS data, so information on customer value is not included when making the decision on whether to accept or reject a reservation request. This can lead to suboptimal decisions. For example, if a restaurant knew that people who booked at the last minute tended to spend more per person than those who book early, they could restrict availability until closer to the day of dining. Or, if restaurants found that people who booked online had a higher average check per person and an average party size that better matched the restaurant's table mix, they might decide to restrict availability for non-online reservations.

This lack of system integration is analogous to a hotel or airline not having information on how much people were willing pay when making their reservation. Essentially, the vast majority of restaurants take reservations on a first-come-first-served basis and do not consider customer value when making their reservation decision.

\section{Tools}


The RRM infrastructure also includes decision support tools that can help managers make better data-based decisions. For example, BI tools extract POS data and summarize it into easily interpreted results in which managers can quickly see their party size mix, their meal durations, server performance and menu item performance. In addition, they may provide restaurants with suggestions on how to improve server performance or to detect fraud. Another example of a tool would be the internal spreadsheets that many restaurants use to try to convert their POS and other data into more actionable form.

\section{Systems}

Currently, there are no integrated RM systems for restaurants. A RRM system would integrate the POS, reservations and customer relationship management (CRM) systems. If the POS and reservations data were integrated, restaurants would have information on customer spending behavior before making the decision on whether to take a reservation. Moreover, if the CRM system were also integrated, restaurants would know which customers purchased which menu items, how much they spent and how often they came. They could use this information to help design better promotions, but also to make better reservations decisions.

\section{Culture}

In order for RRM to succeed, the organization must have a strong RM culture in place. RM is a different way of thinking for most restaurant operators and staff and if not approached with care, RRM may be met with resistance as it may be seen as a challenge to current practice. Given this, RRM initiatives typically need to start off slowly in order to gain buy-in from restaurant operators and staff. In 
addition, performance metrics will need to change as common RM metrics such as occupancy and revenue per available inventory unit are not commonly used in the restaurant industry.

\section{THE PILLARS}

The five pillars of RRM consist of the traditional four Ps of marketing (product, promotion, price and placement) along with a fifth, people. Each will be discussed in more detail below.

\section{Product}

Restaurants sell food and beverage and use their menu as their sales platform. Operators need to determine which and how many menu items to offer, the mix of those items and have the capability to analyze the relative profitability and popularity of their various menu items. While menu engineering models have been proposed (for example, Kasavana and Smith, 1982; Pavesic, 1983), analytical and

empirical research on how restaurants can make better menu item and mix decisions would be valuable to the restaurant industry.

\section{Placement}

Restaurants need to determine the optimal placement of their tables, their guests and the items on their menu.

Table placement: Table placement includes not only the optimal mix of tables (for example, Thompson, 2002; Thompson, 2003; Kimes and Thompson, 2004, 2005), but also where to 
physically locate the tables and the types of tables to use (for example, Kimes and Robson, 2004; Robson et al , 2011). In addition, restaurants must decide on whether they will keep a static table mix or vary it by season, day of week or time of day. Studies that furthered our knowledge of table mix, combinability, table location and table type would prove useful to the restaurant industry.

Guest placement: Guest placement optimization helps ensure that the restaurant not only selects the right guests, but also that they better control the guest experience. It includes reservation system design, controlling meal duration, forecasting, optimization and table assignment. While research on reservation system design has been conducted (for example, Bertsimas and Shioda, 2003; Thompson and Kwortnik, 2008; Alexandrov and Lariviere, 2012), limited research on forecasting, optimization and table assignment has been published. Research that builds on the previous studies on reservation system design and starts to address forecasting, optimization and table assignment problems would be extremely helpful to the restaurant industry.

Reservation system design: When designing the reservation system, restaurants need to decide which platform(s) to use (online, mobile, telephone), the reservation interval (amount of time between successive reservations), the number of reservations to allot to each interval, the expected length of the meal by meal period, day of week and party size, and the amount by which to overbook.

Controlling meal duration: By having a better understanding of meal duration and variance by party size, meal period, day of week and season, restaurants can make a more informed decision on the optimal reservation interval. In addition, restaurants must be careful with how they control meal duration because of the potential negative impact on customer satisfaction (Noone et al, 2009, 2012). 
Forecasting: In order to be able to select which reservation requests to accept, restaurants need to develop forecasts by party value and party size by day of week, time of day and time of year. In addition, they can use booking curve data to help develop better forecasts.

Optimization: The RRM system would use the forecast to determine the optimal amount of inventory by booking channel and time of booking by day of week, time of day and time of year. In addition, the RRM system would select the most valuable reservation requests to accept. If a restaurant chooses not to optimize its table mix because of financial considerations, it could instead optimize the party size based on their current table mix.

Table assignment: Finally, the RRM system would assign guests to the optimal table based on expected meal duration, guest preferences, expected need for table combination and server scheduling.

Menu placement: The RRM system needs to design the menu (whether it be on paper, online or mobile) so that it maximizes profit. Menu design decisions include where to place a menu item (page or order within a category), whether to highlight a particular menu item, which description to use, the way in which price is presented and which font and colors to use. A number of articles have addressed menu design (for a good overview, see Yang et al, 2009 and Yang, 2012), but menu design remains a very fertile area for future research.

\section{Price}

A RRM system also needs to provide restaurants with information with which to make price elasticity and price optimization decisions. In addition, restaurants using RRM must incorporate various psychological and strategic concepts into their pricing approach. 
Price elasticity: A RRM system needs to help restaurants make better pricing decisions by developing menu item price elasticities and cross-elasticities. By having this information, restaurants can make better decisions of which prices to charge and can use this to understand the impact that these price changes may have on demand. Good information on price elasticity can also help restaurants determine optimal menu mix and also assist with developing more effective bundled products (for example, fixed menus or packages). While there is abundant research on price elasticity, research that directly addresses this in the restaurant industry is extremely limited.

Psychological pricing principles: For menu pricing to be successful, restaurant operators should also deploy various psychological pricing strategies including contrast pricing (for example, Ariely and Wallsten, 1995; Yang, 2013) and framing (for example, Kimes and Wirtz, 2003; Wirtz and Kimes, 2007). When selecting and designing these processes, operators must also consider their perceived fairness as fairness perceptions have been shown to influence long-term customer satisfaction.

\section{Promotion}

As with most businesses, restaurants offer promotions so that they can build demand for off-peak periods. In general, the decision of which type of promotion to offer is rarely analytically based. A RRM system should be able to (i) identify periods that operators should consider offering promotions, (ii) provide analytical tools for helping restaurants decide on the type of promotion to offer and for assessing the performance of the various promotions. Ideally, the RRM system would also include CRM information to help better target promotions. Studies that address how best to address these issues represents a fertile area for future research. 
Promotion also includes an analysis of which menu items to feature on the menu and which menu items to have servers suggest. This ties in directly with the menu design decision (placement), pricing and server mentoring (people).

\section{People}

The RRM system should also help restaurants make better decisions on staffing roles and levels, help provide better guidance and training to servers, and provide performance metrics that accurately assess restaurant and staff performance.

Staffing: Restaurants need to decide on the number and types of employees to schedule by day of week, time of day and season. If restaurants understaff, revenue opportunities are lost; conversely, if they overstaff, they incur unnecessary costs and profit suffers. Whereas research on labor scheduling certainly exists (for example, Thompson, 1993, 1995a, 1997), limited research tying labor scheduling to profitability exists (for example, Thompson, 1995b).

Guidance/training: A RRM system should use transaction and CRM data to assess server performance and help provide constructive feedback to the server. Research that assessed the best way in which to do this would prove valuable to the restaurant industry.

At the most basic level, a simple matrix that compares average check and meal duration could help identify servers who are serving guests faster than average at the expense of a lower check average or those who are achieving a higher average check at the expense of a longer meal duration. When this sort of analysis is used in conjunction with CRM data, restaurants can also assess the impact on customer satisfaction. 
POS/transaction level data: A RRM system could also use POS/transaction level data to assess what servers are selling and to give them guidance on how to increase their average check by selling more profitable menu items without compromising meal duration or customer satisfaction.

\section{CONCLUSION}

RRM has been discussed for the past 15 years and represents a fertile area for future research. Additional research is needed in ways of developing the internal infrastructure necessary for successful RRM implementation, methods for better managing the menu mix, approaches to developing and analyzing the success of promotions, determining pricing decisions and strategy and ways of better deploying restaurant employees.

A variety of research opportunities exist within developing and understanding the necessary internal infrastructure. Research that addresses the data issues, lack of system integration, tools that could be used to make RM decisions would be quite beneficial and work on how to develop an integrated RRM system would provide great value. These topics, along with developing the appropriate internal RM culture, present both managers and researchers with many interesting challenges.

Research and tools that help restaurants determine which items to sell, how to price them and how to analyze profitability would be very beneficial to the restaurant industry. In addition, further work on psychological pricing principles could provide restaurant operators with guidance on how to develop their pricing strategies.

The area of placement offers numerous opportunities for improvement. Further studies on table mix, table location and table type would be useful. In addition, guest placement raises a myriad of research and managerial questions. Studies on how best to design restaurant reservations systems that take 
into account demand, meal duration, customer value and table assignment would be extremely beneficial. Menu design is another fertile area for future research.

Finally, research opportunities also exist within promotion and people. Studies on how to design and assess effective promotions would have great value as would research on how restaurants can best deploy, train and mentor their employees.

In conclusion, improvements in RRM hold great promise and excitement for both managers and researchers. Our intent in this article was to present a framework for visualizing the future of RRM and to identify fertile areas for future research. Our challenge to researchers and managers is to address some of the questions raised in this article and to submit the results of their studies and applications to the special issue on RRM (www.palgrave-journals.com/rpm/index.html). 


\section{REFERENCES}

Alexandrov, A. and Lariviere, M.A. (2012) Are reservations recommended? Manufacturing and Service Operations Management 14 (2): 218-230.

Ariely, D. and Wallsten, T.S. (1995) Seeking subjective dominance in multidimensional space: An explanation of the asymmetric dominance effect. Organizational Behavior and Human Decision Processes 63 (3): 223-232.

Bertsimas, D. and Shioda, R. (2003) Restaurant revenue management. Operations Research 51 (3): $472-$ 486.

Kasavana, M.L. and Smith, D.I. (1982) Menu Engineering . Lansing, MI: Hospitality Publishers.

Kimes, S.E. (2004) Revenue management: Implementation at Chevys arrowhead. Cornell Hotel and Restaurant Administration Quarterly 44 (4): 52-67.

Kimes, S.E. (2005) Restaurant revenue management: Could it work? Journal of Revenue and Pricing Management 4 (1): 95-97.

Kimes, S.E., Chase, R.B., Choi, S., Lee, P. and Ngonzi, E. (1998) Restaurant revenue management: Applying yield management to the restaurant industry. Cornell Hotel and Restaurant Administration Quarterly 39 (3): 32-39.

Kimes, S.E. and Robson, S.K.A. (2004) The impact of restaurant table characteristics on meal duration and spending. Cornell Hotel and Restaurant Administration Quarterly 45 : 333-346.

Kimes, S.E. and Thompson, G.M. (2004) Restaurant revenue management at Chevys: Determining the best table mix. Decision Sciences Journal 35 (3): 371-391.

Kimes, S.E. and Thompson, G.M. (2005) An evaluation of heuristic methods for determining the best table mix in full-service restaurants. Journal of Operations Management 23 (6): 599-617.

Kimes, S.E. and Wirtz, J. (2003) When does revenue management become acceptable? Journal of Service Research 7 (2): 125-135.

Noone, B., Kimes, S.E., Mattila, A. and Wirtz, J. (2009) Service encounter pace: Its role in determining satisfaction with hedonic services. Journal of Service Management 20 (4): 380-403.

Noone, B.M., Kimes, S.E. and Wirtz, J. (2012) The effect of perceived control on consumer responses to service encounter pace: A revenue management approach. Cornell Hospitality Quarterly 53 (4): 295-307.

Pavesic, D.V. (1983) Cost/margin analysis: A third approach to menu pricing and design. International Journal of Hospitality Management 2 (3): 127-134.

Robson, S.K.A., Kimes, S.E., Becker, F.D. and Evans, G.W. (2011) Consumers' responses to inter-table spacing in restaurants. Cornell Hospitality Quarterly 52 (3): 253-264. 
Thompson, G.M. (1993) Accounting for the multi-period impact of service when determining employee requirements for labor scheduling. Journal of Operations Management 11 (3): 269-287.

Thompson, G.M. (1995a) Improved implicit optimal modeling of the labor shift scheduling problem. Management Science 41 (4): 595-607.

Thompson, G.M. (1995b) Labor scheduling using NPV estimates of the marginal benefit of additional labor capacity. Journal of Operations Management 13 (1): 67-86.

Thompson, G.M. (1997) Labor staffing and scheduling models for controlling service levels. Naval Research Logistics 44 (8): 719-740.

Thompson, G.M. (2002) Optimizing a restaurant's seating capacity: Use dedicated or combinable tables? Cornell Hotel and Restaurant Administration Quarterly 43 (4): 48-57.

Thompson, G.M. (2003) Optimizing restaurant-table configurations: Specifying combinable tables. Cornell Hotel and Restaurant Administration Quarterly 44 (1): 53-60.

Thompson, G.M. (2010) Restaurant profitability management: The evolution of restaurant revenue management. Cornell Hospitality Quarterly 51 (3): 308-322.

Thompson, G.M. and Kwortnik, R.J. (2008) Pooling restaurant reservations to increase service efficiency. Journal of Service Research 10 (4): 335-346.

Wirtz, J. and Kimes, S.E. (2007) The moderating role of familiarity in fairness perceptions of revenue management. Journal of Service Research 9 (3): 229-240.

Yang, S., Kimes, S.E. and Sessarego, M.M. (2009) Menu price presentation influences on consumer purchase behavior in restaurants. International Journal of Hospitality Management 28 (1): 157160.

Yang, S.S. (2012) Eye movements on restaurant menus: A revisitation on gaze motion and consumer scanpaths. International Journal of Hospitality Management 31 (3): 1021-1029.

Yang, S.S. (2013) The attraction effect: An overview, its fragility and a meta-analysis, Cornell University School of Hotel Administration. Unpublished PhD Dissertation. 